\title{
28. Improving Supply Chain Performance through Business Process Reengineering
}

\author{
Andréa Wattky, Gilles Neubert \\ University of Lyon2, Bron, FRANCE \\ [andrea.wattky@wanadoo.fr; gilles.neubert@univ-lyon2.fr
}

\begin{abstract}
Customer satisfaction and service reliability are not any more the assets but the unavoidable condition for a company to be accepted as a supplier of a product or service. The creation of value added in a company concerns all functions and specifications that are involved in delivering a product or service to the customer. Part of that value enhancing chain is the Supply Chain Management (SCM) conception which is defined as all management principles by which the supply chain is considered as a whole.
\end{abstract}

\section{INTRODUCTION}

Our environment has changed during the past few decades and is more complex today then ever. It seems quite often to be very disorderly and not foreseeable and requires better economic performance. Market globalization had severe consequences for business; competition is fierce, faster and more reactive every day.

Cultural and socio-economic changes have been favored by new information and communication technologies and new relationships within and between organizations. However, in spite of technology investments, productivity did not have the expected significant effects (Grover and Malhorta, 1997). The concept of business process reengineering (BPR) thus appeared; literature witnesses this phenomenon and several books confirm this tendency (Hammer andChampy, 1993) and (Davenport, 1993). This change has been largely recognized (Davenport, 1993), (Stevens, 1989), etc. and today companies try to decompartmentalize their departments, services, and functions in order to end the existing silo organization and to establish integrated and transverse organizations (Kramer and Tyler, 1995).

The Supply Chain Management (SCM) concept is considered as a major stake to gain a competitive advantage over their competitors (Porter, 1985) and (Lynch, 2000). It describes the manufacturing and movement of a good or service starting from the origin of an order until its distribution to the final customer and thus represents an evolution from an intra-company functional integration over an internal corporate logistics integration to at last, an external integration in a logistic network, that is extended upstream to suppliers and downstream to customers.

SCM puts forward the process engineering and reengineering for the company reorganization, therefore companies seek for new ways and solutions in order to respond to this organizational challenge (new forms of management...) concerning the internal level (federate applications...) as well as the external level 
(synchronized processing...). A new challenge for companies concerns also the creation of alliances and partnerships (work in network and through projects, assume interdependency, and develop process rhythms...) (Mentzer, 1999). Exchanging and sharing of information to attest performance towards the different actors, detecting the expectation progress, etc. becomes thus essential for a company today.

Business environment is not a stable situation anymore (pipeline, supply chain) but it belongs to a supply chain network (extended and transverse enterprise). In the following section, we will try to analyze and propose different concepts for process modelling.

\section{PROCESS MODELLING TECHNIQUES}

The supply chain is the combination of multiple processes, which contribute to the creation of value added for an external customer. It includes and is closely related to the concept of process management and process reengineering.

There are different techniques and methods for modelling and remodelling company processes. When choosing one a or number of such techniques, one needs to keep in mind that a process consists in multi-actor activities, which are carried out through time and space; the links between these activities and the activities themselves may belong to different functions and even to different organizations (extended enterprise). The process is consequently considered as the means by which the organization reaches its objectives.

Companies model and remodel their processes mostly through reference models (standard of the ASLOG, the Supply Chain Council's SCOR-model, Framework of Zachman, the model of M. Cooper...), also called standards or architectural frameworks. They are used to represent a problem and to extract useless details in order to provide a better comprehension of that problem in the whole. Those structures and architectural frameworks include standards, languages, and techniques (Bal and Jay, 2004). Their primary objective is to indicate, which information should be captured and by which means this is possible.

Then, there are enterprise modelling tools (Aris from IDS Scheer, MEGA from MEGA International...) that include concepts, meta-models and semantics. The objective of these modelling tools is to support architectural frameworks. There are also modelling techniques (Use Case de UML...), that are often associated with the before mentioned modelling tools. Graphical modelling techniques are particularly interesting because they are very appropriate for a good visualization and communication. Traditionally, techniques like flow charts and data flows are used to model applications.

Finally, one should not forget to mention the description techniques, which support reference models and which are used by organization modelling tools. These are modelling and analysis techniques that provide sometimes implementation examples. The ISO standards are among the most known and put forward the main principles and vocabulary of the management system for quality etc., main guidelines for performance improvement, inter-enterprise relationship requirements, and regulation requirements, which are applicable in order to continually improve enterprise performances. 
In order to understand the hierarchy of the concepts, mentioned above, one needs to distinguish between the terms methodology and methods. The definitions of the (Merriam-Webster dictionary, 2004) are the following

- Methodology:

Efymology: New Latin methodologia, from Latin methodus + -logia -logy

1 : a body of methods, rules, and postulates employed by a discipline : a particular procedure or set of procedures

$2:$ the analysis of the principles or procedures of inquiry in a particular field

- Method

Etymology: Middle French or Latin; Middle French methode, from Latin methodus, from

Greek methodos, from meta- + hodos way

1 : a procedure or process for attaining an object: as a (1) : a systematic procedure,

technique, or mode of inquiry employed by or proper to a particular discipline or art (2) : a

systematic plan followed in presenting material for instruction $b(1)$ : a way, technique, or process of or for doing something (2) : a body of skills or techniques

$2:$ a discipline that deals with the principles and techniques of scientific inquiry

$3 \mathbf{a}$ : orderly arrangement, development, or classification; $\mathbf{b}:$ the habitual practice of orderliness and regularity

4: capitalized : a dramatic technique by which an actor seeks to gain complete identification with the inner personality of the character being portrayed.
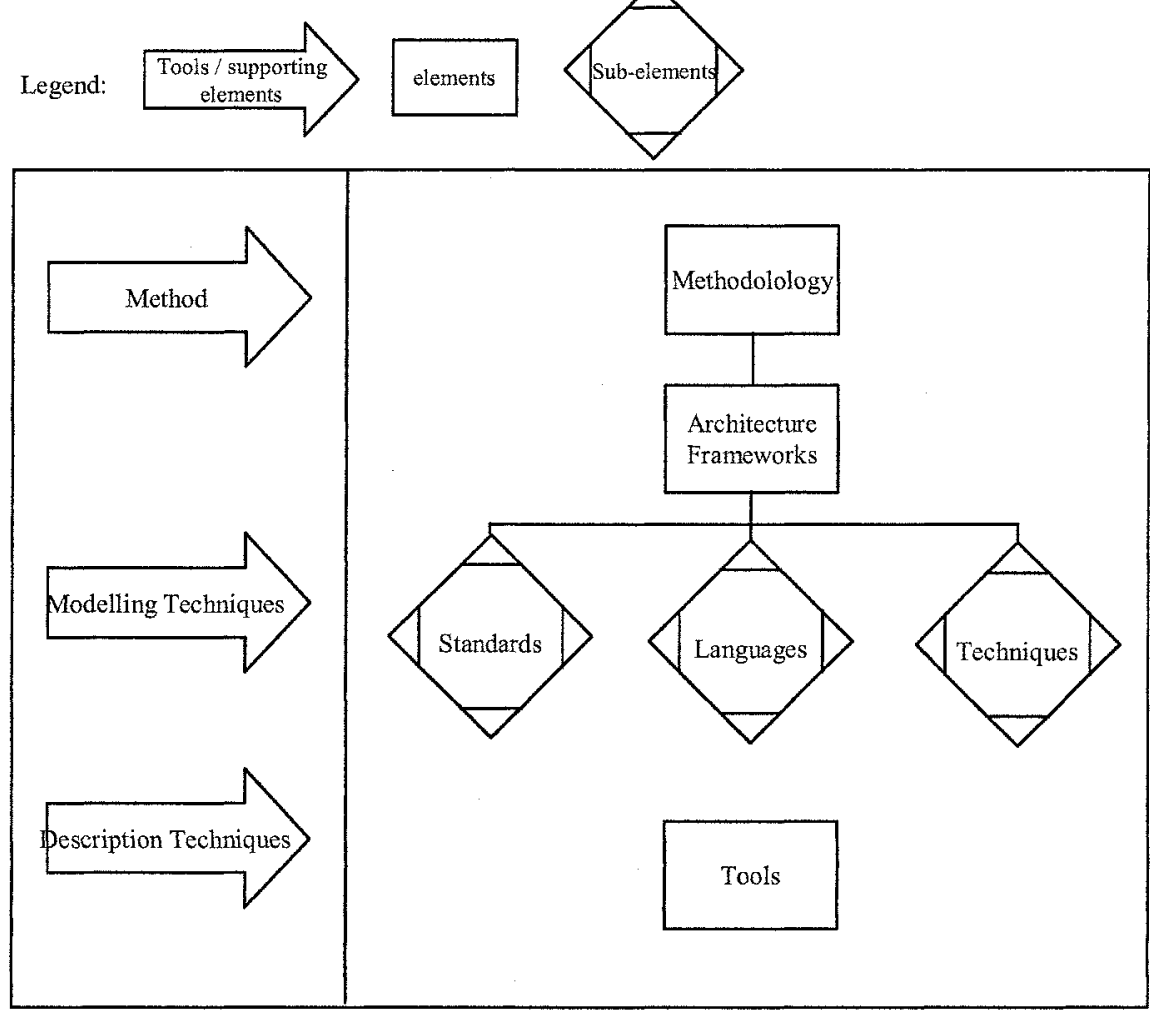

Fig. 1 State of the art overview 
One can assume that the term methodology contains one or more methods. The state of the art concerning the architectural frameworks, methods, methodologies etc. can be represented like in Fig. 1.

In the next section, we will tempt to present two different modelling techniques, which put the processes in the heart of the company's transformation actions thanks to the process reengineering approach. We will try to explain how the use of a standard framework and business process reengineering (BPR) can help defining, organizing, and implementing optimized processes in a supply chain network.

\section{TWO MODELLING TECHNIQUES IN DETAIL}

A process is a continuation of supple steps and is based on knowledge management. It needs to be built up in a manner to best serve customer needs and requirements at the lowest cost for the company. Thus one can say that the difficulty of the process implementation does not only lie in the complexity of its realization and execution, but also in the conducting of transverse change.

In order to create a mutually accepted and common understanding, one needs to talk the same language.

\subsection{The SCOR-model}

We chose to go more into detail concerning the SCOR reference model for different reasons: this architectural framework proposes many enterprise modelling tools and uses as description technique process charts for a visible and easy understanding of the company organization.

SCOR can be considered as a standard approach to modelling a supply chain because there are common terms and definitions for processes and predefined measures for supply chain performance. Many companies use this standard for their process modelling and analysis.

The Supply Chain Council (SCC) is an independent, non-for-profit, global corporation, formed in 1996 as a grassroots initiative in order to develop a standard supply chain framework. The SCC mission is to perpetuate the use of the SCORmodel (Supply Chain Operations Reference model), that combines elements of business process reengineering, benchmarking, and best practices into a single structure that represents a process organization applicable in every company, internally and externally, thus allowing to establish an integrated supply chain network.

SCOR, which has been developed to describe all activities leading to customer satisfaction, describes 5 main integrated management processes of any supply chain: Plan (planning), Source (procurement), Make (production), Deliver (delivery), and Return (area of post-delivery customer support).

In order to combine the strategy of the company with the supply chain, the SCOR-model is built according to a top-down approach as show in figure 2 through 3 different levels:

- Level one defines the scope and content for the Supply chain Operations Reference-model. The basis of competition performance targets is set this level (strategy, business rules...). 
- At level two, a company's supply chain can be "configured-to-order" from core "process categories." Companies implement their operations strategy through the configuration they choose for their supply chain (product environment...).

- Companies "fine tune" their Operations Strategy at level three. This level defines a company's ability to compete successfully in its chosen markets, and consists of: process element definitions, information inputs and outputs, process performance metrics, best practices, system capabilities required to support best practices, and systems/tools.

Companies implement specific SCM practices at level four, which is not in the scope of SCOR because it concerns the unique circumstances of each company and cannot be part of a structure which is applicable to any company.

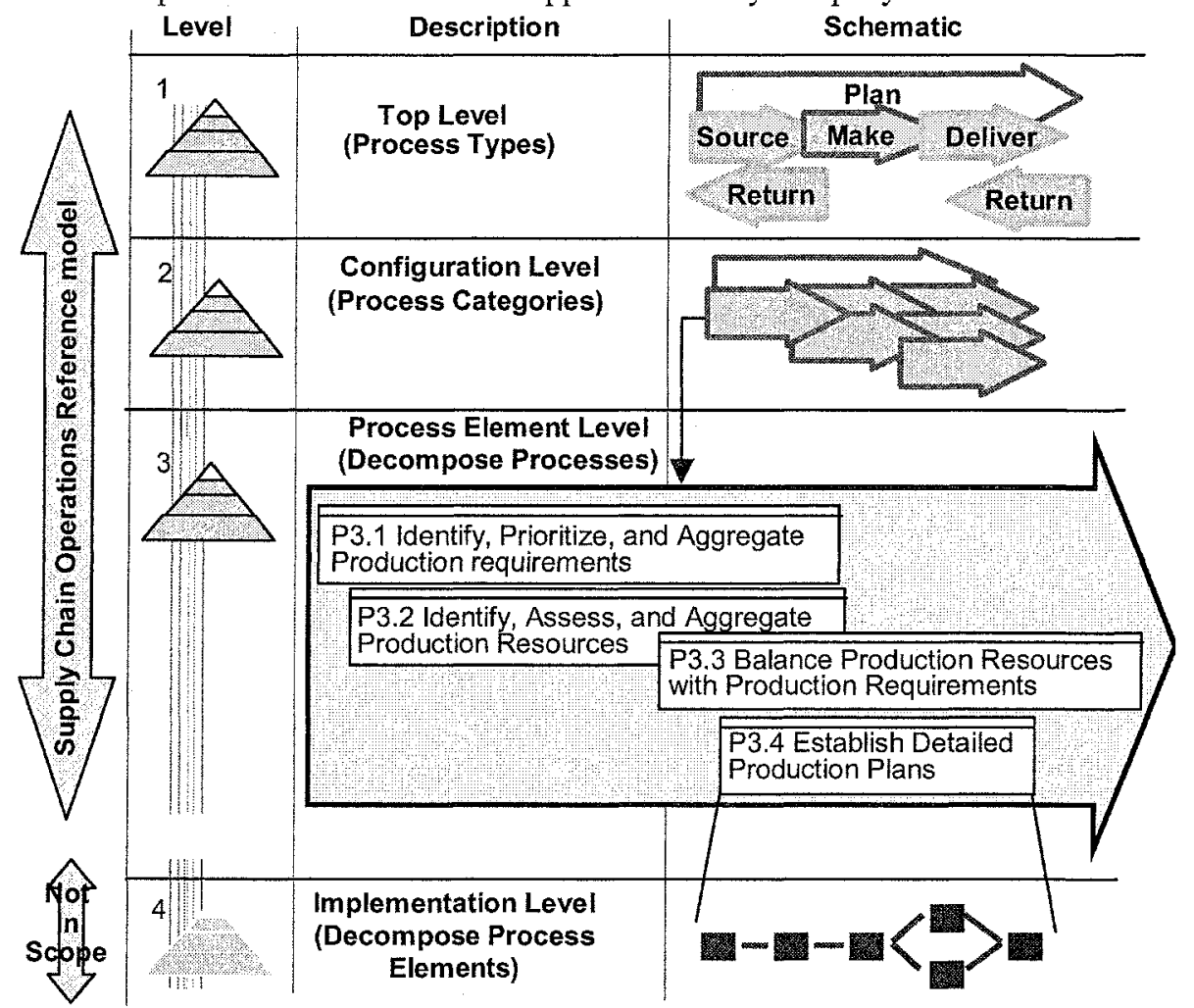

Figure 2: Three Main Levels of SCOR

Even though SCOR considers technology as a tool that can support a better company organization, the management processes are the ones which are classified as most important $\mathrm{sp}$ that a true interdependency chain of great value between its actors is described and the internal and external company relations are dealt with in an optimal way.

However, the SCOR-model does not have all the answers. There are processes which cannot be described by SCOR. For example, training, marketing or quality are processes out of scope of the SCOR-model. 


\subsection{BPR methodologies}

There are different methodologies for modelling and remodelling processes, called business process reengineering (BPR). BPR is about radical change in the way in which an organization performs its business activities and it involves the rethinking of the business processes followed by their redesign to enhance all or most of its critical measures (cost, service quality, staff dynamics...) (Grover and Malhorta, 1997).

BPR can be done following different viewpoints: process, information technology, organization according to (Gilmour, 1999); process, market or channel according to (Bowersox and Daugherty, 1985) and (Clinton and Closs, 1997).

One can comprehend BPR through different ways: one can analyze what work is done, who does it and how, when this work is done and who the decision maker is. A process includes functions, behaviors, organization, information, decisions and resources. The functions concern the activities and elements of the process. The behaviors focus on the "when" and the "how" of the process. The organization represents the process execution and the mechanisms through which interaction and transfer of content takes place. Information represents the details or entities that are manipulated by the process; they can be data and relationships associated with the process.

BPR, hence the transformation of a vertical organization (traditional hierarchy) into an organization, based on its processes (horizontal organization), requires to rethink the existing company processes. Nevertheless, one should not forget that the different actors of a supply chain are at different work levels and that therefore they do not consider the process the same way. The vision of these actors is thus neither global nor the same for each of them. Their performance objectives are not the same either (Nathalie Fabbe Costes, 2004). For instance, for those who are concerned by physical flows, cost control is the most important performance indicator. Those who are concerned by quality have totally different priorities like the delivery reliability and delay optimization to improve and secure the physical flows.

This means that the process functioning and the used technology depends totally on the motivation of people and their ability and will of learning and adapting to change. Difficulties can also appear during the information transmission between the different functions of a company. Thus, a clear and simple collaboration between the different actors is necessary to create an integrated and transverse organization (Kramer and Tyler, 1995). Therefore, one needs to describe processes, which allow to share information and to accelerate the reactivity of the company. Good interactions are necessary within the processes and this in spite of the different time and culture horizons and different objectives of all actors. That's also why simplifying and standardizing have become key words today because more a product or an information circulate with different functions to follow a process flow, more there are risks of delay, bad interpretations, and value destruction.

BPR concerns the reorganization of tactical and strategic processes, made in light of people, process, and technology and it is always guided by an "as is - to be" methodology of understanding the current process situation before making any changes. 
In the following two sections, we will try to clarify both process modelling techniques presented above through two case studies: one using the SCOR-model, and one using BPR for analyzing and optimizing business processes.

\section{FIRST CASE: PROCESS IN SCOR SCOPE}

Being considered as a reference model of international standards, SCOR can be considered as a process guide that includes performance indicators, best practices, and benchmark information. The following process analysis will rest on three modelling stages: the SCOR process charts are used for the process description and visualization; common notations and definitions help to measure supply chain performance and get to the desired process situation; and thus the final process description and validation.

\subsection{AS IS process description \& SCOR comparison}

First of all, the material flow and the information/work flow of a process are described in an AS IS situation and compared with the flow proposed by SCOR (figure 3). When this is done, the actual process situation and SCOR allow determining all barriers in the process structure and its fluidity bottlenecks.

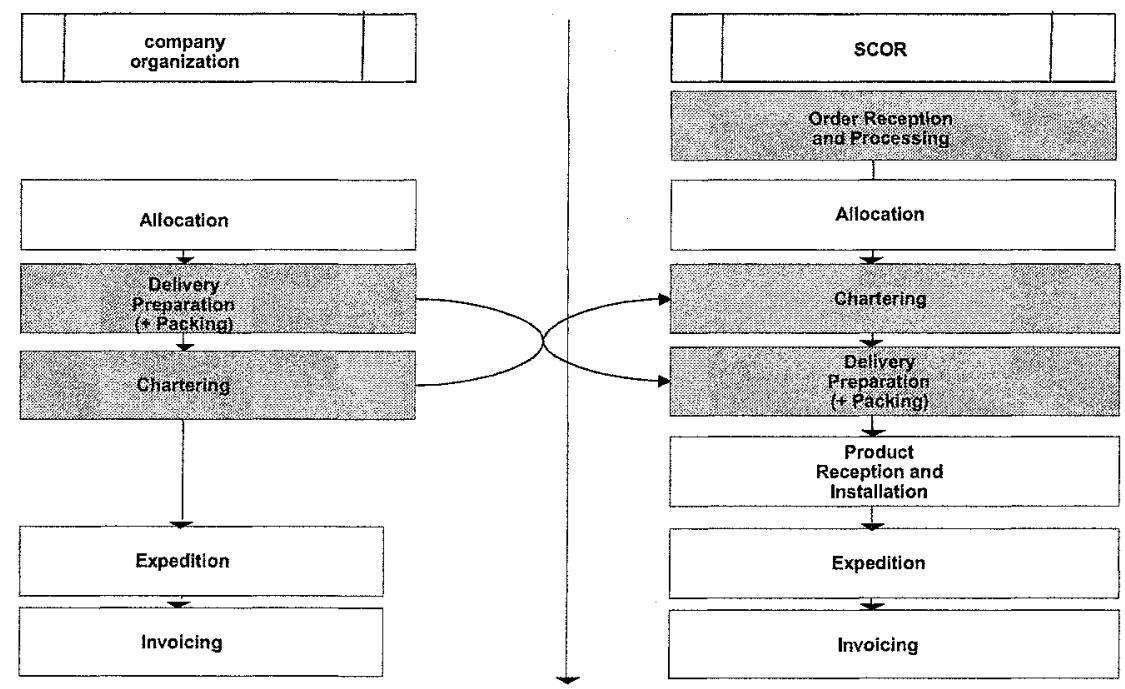

Figure 3: AS IS company and SCOR comparison

\subsection{SCOR implementation \& KPI/BP analysis}

SCOR being a guide of process and sub-process identification, and optimization opportunity identification, this step concerns the SCOR implementation in the AS IS situation in order to compare all data (inputs, outputs, sub-processes...). 


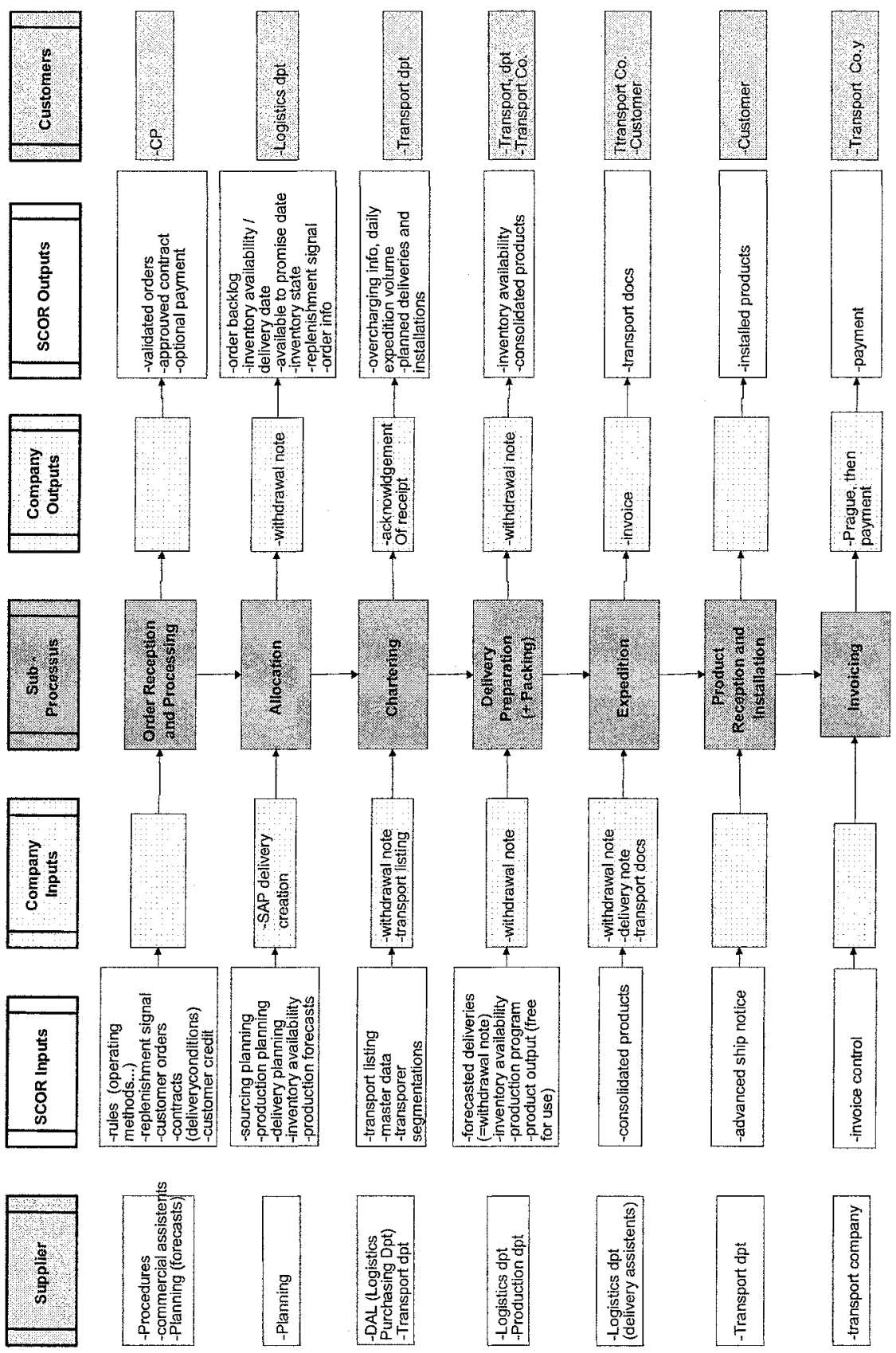

Figure 4: SCOR Implementation in an AS IS Process

As shown in Fig. 4, the model defines many different sub-process and their inputs and outputs so that the company can check and compare those with the existing ones and analyze their performance. In order to optimize this process, it is of primary 
importance to include measurement of the internal and external process performance because it allows making different adjustments (design, marketing...).

So as to facilitate the choice of pertinent performance indicators (KPI), SCOR recommends four basic performance attributes (service, cost, reactivity, and resource usage) on which performance measures are built upon.

In order to realize the TO BE status of the new process, action plans have to be determined. At this stage of the process analysis, SCOR also proposes a useful tool: the best practices (BP), which aim at evaluating the maturity of a process to help defining the actions, which are to be undertaken, in order to optimize the process in the best possible way.

\subsection{TO BE process validation \& process GO LIVE}

The last step is then to describe and communicate the TO BE process as shown in figure 5. The process flow is optimized and fluid, and all possible adjustments for the TO BE process have been made.

SCOR is helpful concerning the interactions between the individuals in charge of the sub-processes and other multiple tasks within the process and facilitates the final implementation of the optimized process (GO LIVE).

\section{SECOND CASE: PROCESS OUT OF SCOR SCOPE}

Business process reengineering methodologies can help to improve and optimize processes that are not in the scope of the SCOR-model because it's a matter of an approach that puts the processes in the heart of the company's transformation actions. This helps to remove any work surplus in the processes and to automate the majority of tasks. It is a matter of exploiting efficiency and productivity opportunities across multiple inputs into the supply chain; establishing hence an integrated supply chain process.

\subsection{AS IS description \& pointing out of dysfunctions}

One first describes the AS IS situation of the process. No comparison with SCOR is possible at this point. Through audits, all interactions between the actors and the different sub-processes are put forward. All process dysfunctions within these are highlighted as one can see in figure 6.

The critical path concerning these dysfunctions can thus be analyzed, stating the main problems in the process.

\subsection{TO BE description, analysis, \& action plan implementation}

The next step concerns the description of the TO BE process by putting in place different action plans, which emphasize for each actor where his improvement areas are, concerning which activities. This is done through regular meetings with all actors for a simple process, and as for complex processes through meetings with all group pilots.

\subsection{TO BE process, action plan validation \& process GO LIVE}

At the next stage of process optimization, priorities for all action plans are set as shown in figure 7. 


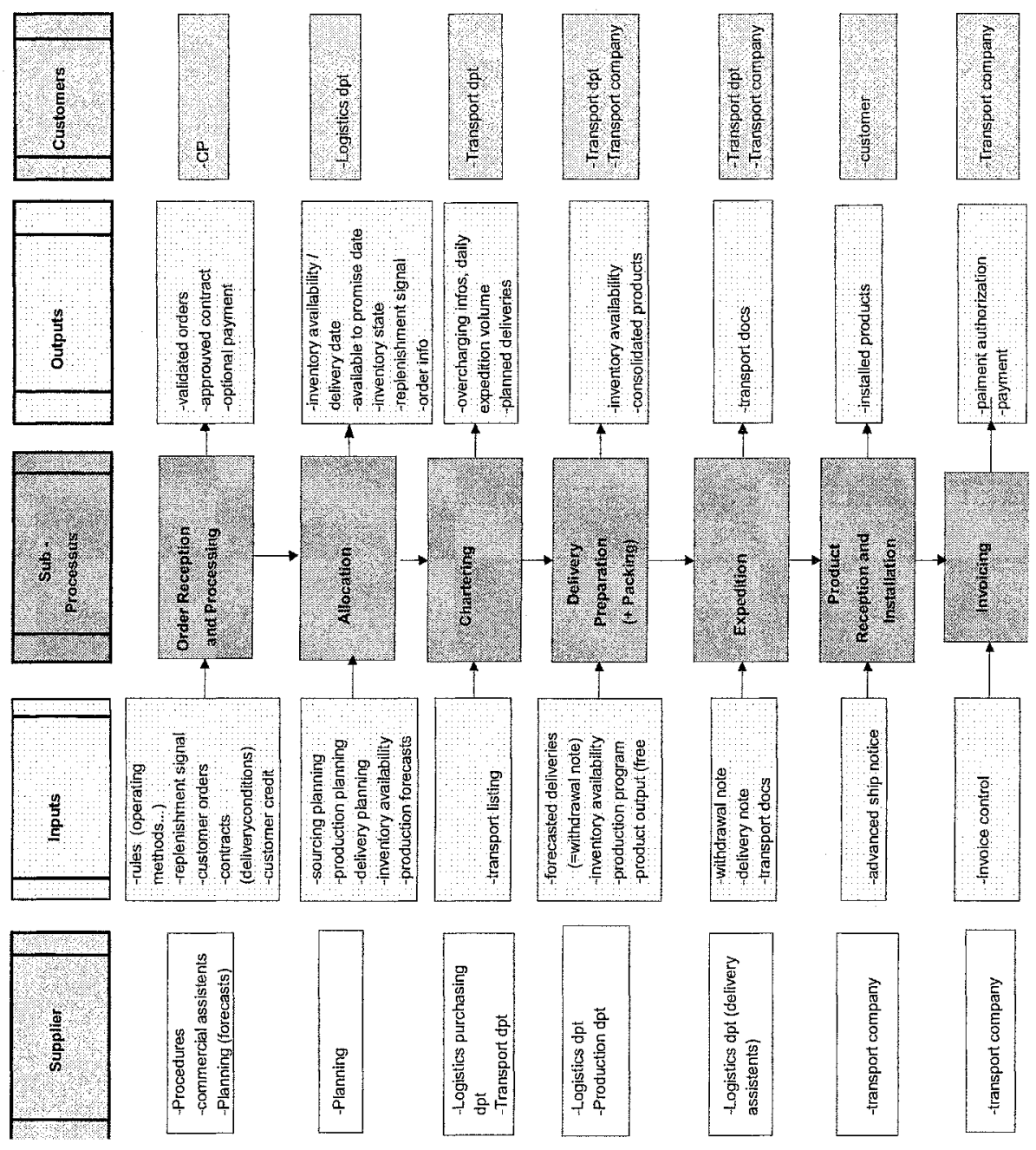

Figure 5: TO BE Process

In order to follow-up these plans of action, the regular meetings help to put forward new questions and/or dysfunctions concerning the process and to indicate the plans of action, which succeeded (GO Live). During the last piloting meeting, every plan of action is reviewed and validated thus determining the success of their implementation (GO LIVE).

\section{LESSONS LEARNED}

To guarantee the lasting quality and the efficiency of rewritten and optimized processes, it is imperative that the company's reorganization is in the scope of strategic company processes. It is also essential to appoint the individuals in charge of each process and sub-process so that their continuous improvement is assured. In order to reach the performance optimum of the "new" processes, it is useful to gather 
the operational units that depend hierarchically on the person in charge of the process. That way, neither the different functions (production, marketing, etc.) nor the different divisions within a company (products, markets) constitute an obstacle for these individuals to use their different resources and competencies in an optimal way. At this point of company reorganization SCOR and BPR help gathering all efforts and contributions of each individual of the company so as to combine them in a common process of value added.

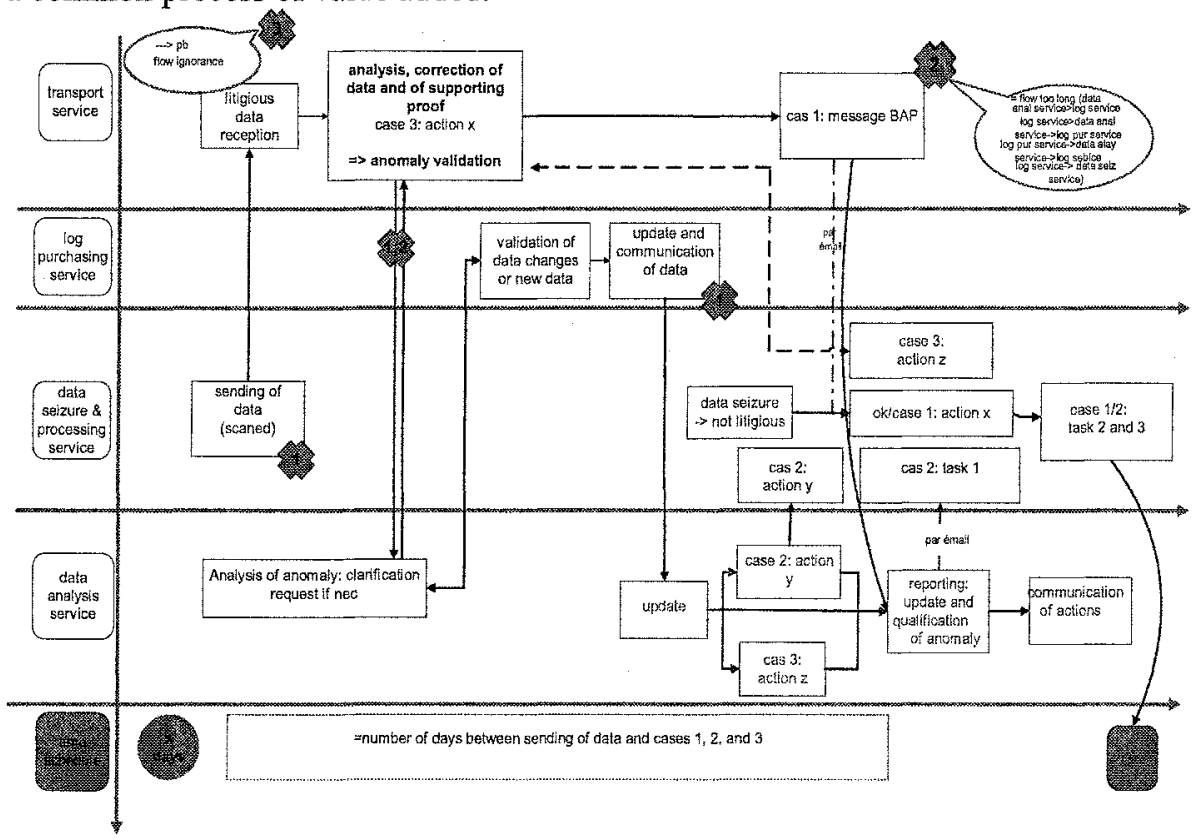

Figure 6: AS IS Process Flow

However, a company should not embark on such a process reengineering analysis without having profoundly thought about the reasons and the possible obstacles concerning this company and process reorganization. Using SCOR and BPR for the process optimization, one needs to simplify and base the process configuration on two levels: the material flow and the information/work flow. Once, the processes described and analyzed, relevant and adapted indicators and BP should be used to measure the success of the efforts made.

Organizations, which are based on processes, seem to be most capable to learn and generate continuous progress because they are open minded aiming at external objectives (customer satisfaction, service level, etc.). Companies want to become best-in-class in their industry sectors and markets and seek to become most agile thanks to multifunctional entities.

Process reorganization needs to be made in light of people, process and technology. Not only the tactical and strategic processes need to be optimized, but also the individual users motivation and the technology they use to operate. Without all three molded into a final methodology, continuous improvement cannot take place. 


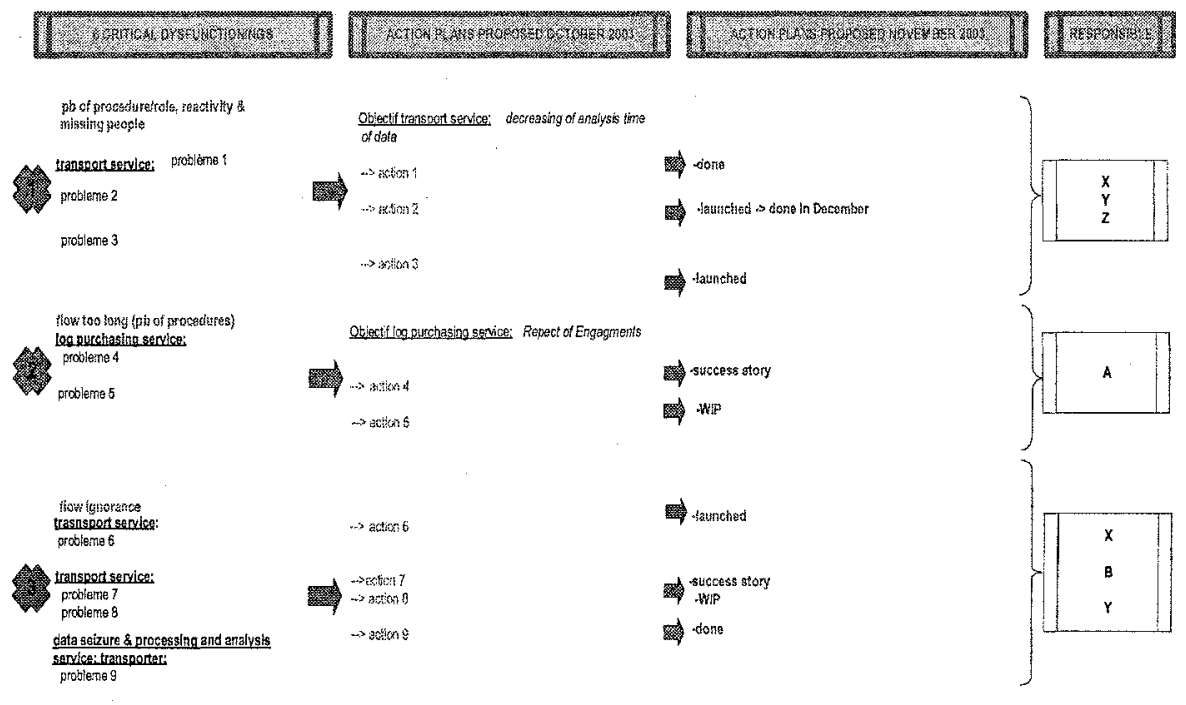

Figure 7: Action Plans \& Follow-up

In this present paper the process point of view has been examined with as main objective to cross different existing techniques and methods. Thus a common and single methodology of process modelling and remodelling could be established and resumed through the analysis of an "as is" and a "to be" situation in order to validate the "go life" of the new company organization.

These days, new areas of research have appeared with a focus on the communicating organization, based on mechanisms of the exchange and the coordination of resources and competencies. Future studies on how to best reach this objective will be done in the context of the evolution of inter-and intra company relationships. Information exchange and information sharing will be the main focus concerning the organizational change, from simple contractual relationships until collaborative supply chains creating supply chain networks (alliances and partnerships).

\section{REFERENCES}

Grover,V., Malhorta,M.K (1997). Business process reengineering: A tutorial on the concept, evolution, method, technology and application. Journal of Operations Management. no. 15.

Hammer,M., Champy,J. (1993). Reengineering the corporation: A manifesto for business revolution. Harper Collins. New York.

Davenport,T.H. (1993). Process Innovation: Reengineering Work Through Information Technology. In Harvard Business School Press. Boston.

Stevens, G. (1989). Integrating the supply chain. Physical Distribution \& Materials Management. no 19 8. pp.3-8.

Kramer, R.M., Tyler, T.R. (1995). Trust in Organizations: Frontiers of Theory and Research. Berkeley, CA, Sage Publications.

Porter, M.E. (1985). Competitive advantage: creating and sustaining superior performance. New York, Free Press. Chapter 2. 
Lynch, D.F. (2000). The effects of logistics capabilities and strategy on firm performance. Journal of Business Logistics. 21 2. pp.47-67.

Mentzer, M.S. (1999). Two heads are better than one if your company spans the globe. In the Academy of Management Executive: no 13. pp89-90.

$\mathrm{Bal}$, J. (2004). Process Analysis Tools for Process Improvement. Proc International Manufacturing Centre, University of Warwick. pp 1-3

Merriam-Webster dictionary. (2004). http://www.m-w.com/netdict.htm, March $29^{\text {th }}$

Gilmour, Peter. (1999). Benchmarking supply chain operations. International Journal of Physical Distribution \& Logistics Management. no 5 1. pp.283-290.

Bowersox, DJ.J, Daugherty, P.J., (1985). Emerging Patterns of Logistical Organization. Journal of Business Logistics: no 81 . pp.46-60.

Clinton, S.R., D.J. Closs. (1997). Logistics strategy: does it exist? Journal of Business Logistics: no 18 1. pp.19-44.

Fabbe Costes,N. (2004). Maîtriser le temps des processus logistiques pour créer de la valeur? Proc Carrefours Logistiques, Paris, France. pp3-7. 